\title{
Modelo híbrido de previsão de séries temporais para possíveis aplicações no setor de geração eólica
}

\author{
Hybrid model of time series forecasting for possible applications in the wind power sector
}

\author{
João Bosco Verçosa Leal Junior ${ }^{1}$, Henrique do Nascimento Camelo ${ }^{2}$, Paulo Sérgio Lucio ${ }^{2}$ e \\ Paulo Cesar Marques de Carvalho ${ }^{3}$
}

\author{
${ }^{1}$ Universidade Estadual do Ceará (UECE), Fortaleza, Brasil \\ ${ }^{2}$ Universidade Federal do Rio Grande do Norte (UFRN), Fortaleza, Brasil \\ ${ }^{3}$ Universidade Federal do Ceará (UFC), Fortaleza, Brasil
}

\section{Resumo}

No presente artigo um inovador modelo hibrido de previsão de séries temporais baseado na combinação de duas funções (linear e não-linear), respectivas dos modelos Holt-Winters e Redes Neurais Artificiais é apresentado. Esse modelo é aplicado em velocidade do vento no nordeste brasileiro, e foi capaz de realizar previsões de curto e longo prazo com boa acurácia. Destaca-se a eficiência do modelo proposto em fornecer perfeitos ajustes aos dados observados, sendo essa afirmativa de acordo com os baixos valores encontrados na análise estatística de erros, por exemplo, com erro percentual de aproximadamente 5,0\%, e também com o valor do coeficiente de eficiência de Nash-Sutcliffe no valor de aproximadamente de 0,96. Esses resultados foram importantes nas precisões encontradas, fazendo com que pudessem acompanhar o perfil das séries temporais observadas, principalmente revelando maiores semelhanças de valores máximos e minimos entre ambas as séries, mostrando assim, a capacidade do modelo em representar caracteristicas de sazonalidade local. Métodos para previsão de velocidade do vento podem constituir em técnica útil no setor de geração éólica, por exemplo, sendo capaz de adquirir informações importantes de que maneira o potencial éólico local poderá ser aproveitado para possível geração de energia elétrica.

Palavras-chaves: Modelo estatístico. Redes neurais artificiais. Velocidade do vento.

\section{Abstract}

In this paper an innovative hybrid model of time series prediction based on the combination of two functions (linear and nonlinear) of the Holt-Winters and Artificial Neural Networks models is presented. This model is applied in wind speed in northeastern Brazil, and was able to perform short and long term forecasts with good accuracy. We highlight the efficiency of the proposed model in providing perfect adjustments to the data observed, being this affirmative according to the low values found in the statistical analysis of errors, for example, with percentage error of approximately $5.0 \%$, and also with the value of the Nash-Sutcliffe coefficient of efficiency of approximately 0.96. These results were important for the accuracy of the data, so that they could follow the profile of the observed time series, mainly revealing greater similarities of maximum and minimum values between both series, thus showing the capacity of the model to represent characteristics of local seasonality. Wind speed prediction methods can be a useful technique in the wind power sector, for example, being able to acquire important information on how local wind potential can be harnessed for possible electric power generation.

Keywords: Statistical model. Artificial neural networks. Wind speed. 


\section{Introdução}

A necessidade de pesquisas que possam fornecer métodos capazes de atenuar poluentes atmosféricos vem crescendo ano após ano. Uma das estratégias para atenuar os gases do efeito estufa na atmosfera provenientes das atividades humanas é o incentivo ao uso dos recursos renováveis de energia, como é o caso da geração eólica (DAI, 2013). O Painel Intergovernamental sobre Mudanças Climáticas (IPCC ${ }^{1}$ ), em seu mais recente relatório lançado em 2014, apontou que o aquecimento global é uma realidade e a contribuição do ser humano é significativa para a ocorrência de fenômenos ligados às mudanças climáticas. Na medida em que houver, cada vez mais, inserção de energias renováveis em matrizes energéticas de diversas nações pelo mundo afora poderá contribuir para ambientes mais saudáveis (PACHAURI et al., 2015).

Em termos de geração eólica na atualidade um método de pesquisa que vem sendo testado, a fim de identificar sua viabilidade trata-se da previsibilidade da velocidade do vento local, seja através de médias mensais ou horárias (LIU et al., 2012; 2015; CAMELO et al., 2016). Kavasseri e Seetharaman (2009) usam o modelo Auto Regressivo Integrado de Médias Móveis (ARIMA), também conhecido por modelagem Box-Jenkins (BROCKWELL \& DAVIS, 2016), para a previsão da velocidade do vento no horizonte de $24 \mathrm{~h}$ em quatro localidades da região de Dakota do Norte nos EUA.

Esse artigo apresentar metodologia de previsibilidade dos ventos, a partir da elaboração de modelagem híbrida combinada de modelos de série temporal com inteligência artificial. Esse modelo poderá auxiliar no setor de geração eólica, por exemplo, adquirindo informações importantes de que maneira o potencial eólico local poderá ser explorado para geração de energia, uma vez que, será possível realizar projeções da intensidade da velocidade dos ventos, e desta forma, planejar o quanto de energia elétrica poderá ser gerada e capaz de atender a demanda.

\section{Material e métodos}

\subsection{Região de estudo e dados coletados}

Os dados de velocidade de vento utilizados nesse artigo fazem parte da torre meteorologica do aeroporto da cidade de Natal $\left(5.75^{\circ} \mathrm{S}\right.$ e $\left.35.35^{\circ} \mathrm{W}\right)$ no nordeste do Brasil, ao nível de $10 \mathrm{~m}$ de altura, e foram doados pelo projeto Airmetar ${ }^{2}$. Esses dados são constituídos de duas formas: (1) em termos de médias mensais equivalente a 144 medições com início em janeiro de 2003 e término em dezembro de 2014; e (2) em termos de médias horárias contendo todos os horários relativo ao ano de 2014, ou seja, 8760 medições. Para aplicação dos dados no modelo proposto foram seguidas as etapas: (I) fase de ajuste - em termos de médias mensais consiste em introduzir os dados observados no modelo de previsão para que seja possível fornecer os respectivos ajustes entre o período de janeiro de 2003 até dezembro de 2014, e em termos de médias horárias consiste em introduzir os dados observados no modelo de previsão para que seja possível fornecer os respectivos ajustes entre o o período de 01/01/2014 até 31/12/2014; (II) fase da qualidade dos ajustes - essa averiguação é realizada mediante a utilização de métodos de acurácia; (III) fase de previsão - serve para ilustrar a capacidade do modelo em realizar projeções da velocidade do vento para o período seguinte aos dados observados, através dos melhores modelos ajustados de duas formas: (1) em termos de médias mensais para os meses do ano de 2015 (longo prazo); e (2) em termos de médias horárias para o dia 01/01/2015 (curto prazo).

\subsection{Modelo proposto}

O modelo hybrid proposto nesse artigo capaz de realizar previsões de velocidade do vento foi elaborado a partir da combinação de duas funções (linear e não-linear) com a finalidade de tentar representar todas as possíveis características da série temporal em questão, e sua representação é dada por,

hybrid $=\mathrm{M}$ prev $+\mathrm{RNA}_{\text {prev/HW }}$

em que:

hybrid - representa a previsão do modelo híbrido proposto.

HW - é a abreviação de Holt-Winters (sendo que HWprev representa a previsão por este modelo o qual é a componete linear), trata-se de um modelo comum da literatura para previsão de séries temporais que envolvem tendência e sazonalidade, e um dos seus pontos positivos é atribuir pesos maiores para observações mais próximas da previsão (BROCKWELL \& DAVIS, 2016). RNA - representa abreviação de Redes Neurais Artificiais (sendo que RNAprev/HW é a componente não-linear utilizada para realizar a previsão dos resíduos gerados pelo modelo $\mathrm{HW}$ ), uma das principais vantagens deste modelos é referente ao fato de ser possível utilizar funções não-lineares para viabilizar ajustes aos dados observados (BROCKWELL \& DAVIS, 2016). A idéia do modelo da equação (1) surgiu baseada no modelo proposto por Zhang (2003), o qual trata de uma combinação do modelo

1 Maiores detalhes em sua página eletrônica http://www.ipcc.ch/.

2 Maiores detalhes conferir na página eletrônica http://www.airmetar.com.br/. 
linear - Auto Regressivo Integrado de Médias Móveis (ARIMA) com uma RNA. Vale destacar a característica inovadora do modelo hybrid na tentativa de realizar previsões de séries temporais.

\subsection{Medidas de acurácia}

Uma das formas de verificar acurácia dos modelos de previsão propostos é através de análise estatística de erros, neste artigo foram utilizadas as seguintes: (a) O Erro Médio Absoluto (MAE); (b) A Raiz do Erro Quadrático Médio (RMSE); e (c) Média do Erro Absoluto Percentual (MAPE). Maiores detalhes sobre estatística de erros em (BROCKWELL \& DAVIS, 2016). Outra medida para identificar a qualidade dos ajustes, trata-se do coeficiente de eficiência de Nash-Sutcliffe (NS), o coeficiente de eficiência pode variar entre - $\infty$ a 1, sendo o valor 1 indicativo de um perfeito ajuste, e conforme (Silva et al., 2008), quando o valor do NS resultar maior que 0.75 , o desempenho do modelo é considerado bom. Para valores de NS entre 0.36 e 0.75 , o desempenho é considerado aceitável, enquanto valores de NS inferiores a 0.36 fazem com que o modelo seja julgado como inaceitável.

\section{Resultados}

A tabela 1 apresenta os resultados da estatística de erros. O modelo hybrid forneceu os menores valores das medidas de erros, por exemplo, o valor de MAPE encontrado foi de 7,70\% no caso mensal, e 14,50\% no caso horário. Esses valores são inferiores aos encontrados no modelo HW, ou seja, quando utilizado separadamente, apresentando respectivamente os valores de MAPE de $9,44 \%$ e $27,37 \%$ em termos de médias mensais e horárias. O fato do modelo hybrid revelar os menores valores das medidas de erros, quando comparado ao HW poderá favorecer para maiores semelhanças entre as séries temporais ajustadas e observadas, principalmente em termos de valores máximos e mínimos da velocidade do vento, e dessa maneira, produzir previsões mais precisas.

Tabela 1 - Análise estatísticas de erros para identificar acurácia dos modelos propostos, para dados mensais.

\begin{tabular}{c|c|c|c}
\hline \multicolumn{2}{|c|}{ Mensal } & \multicolumn{2}{c}{ Horário } \\
\hline Erro - HW & Natal & Erro - HW & Natal \\
\hline MAE $(\mathrm{m} / \mathrm{s})$ & 0,40 & MAE $(\mathrm{m} / \mathrm{s})$ & 1,03 \\
\hline RMSE $(\mathrm{m} / \mathrm{s})$ & 0,50 & RMSE $(\mathrm{m} / \mathrm{s})$ & 1,38 \\
\hline MAPE $(\%)$ & 9,44 & MAPE $(\%)$ & Natal \\
\hline Erro - hybrid & Natal & Erro - hybrid & 0,66 \\
\hline MAE (m/s) & 0,32 & MAE (m/s) & 0,89 \\
\hline RMSE (m/s) & 0,45 & RMSE (m/s) & 14,50 \\
\hline MAPE (\%) & 7,70 & MAPE (\%) &
\end{tabular}

A figura 1 mostra as comparações entre as médias mensais das séries temporais observadas e ajustadas pelo modelo hybrid, sendo que está representada na figura la o valor do coeficiente de eficiência NS de 0,70 que demonstra a eficiência do modelo para fornecer bons ajustes aos dados observados da região de estudo, e em função disto é possível identificar a existência de semelhanças entre as duas séries temporais (observadas e ajustadas), em especial

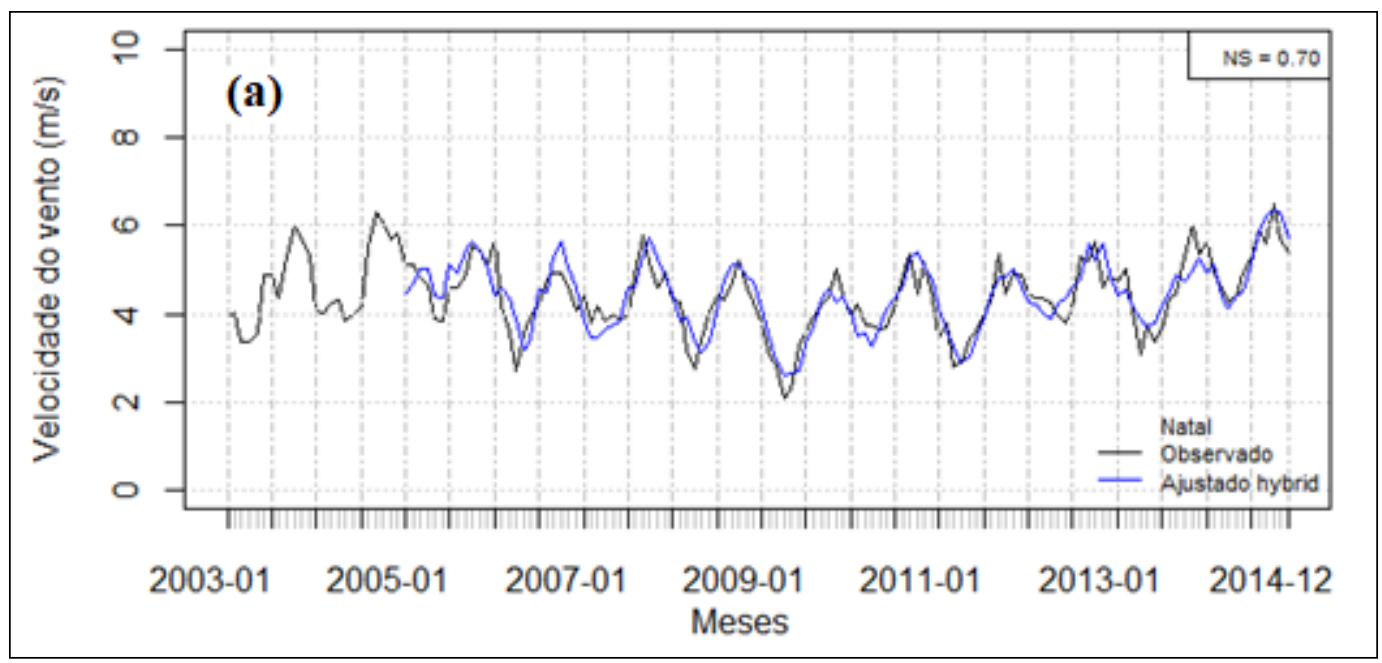

Figura 1a - comparações de média mensal da velocidade do vento (observada e ajustada) 


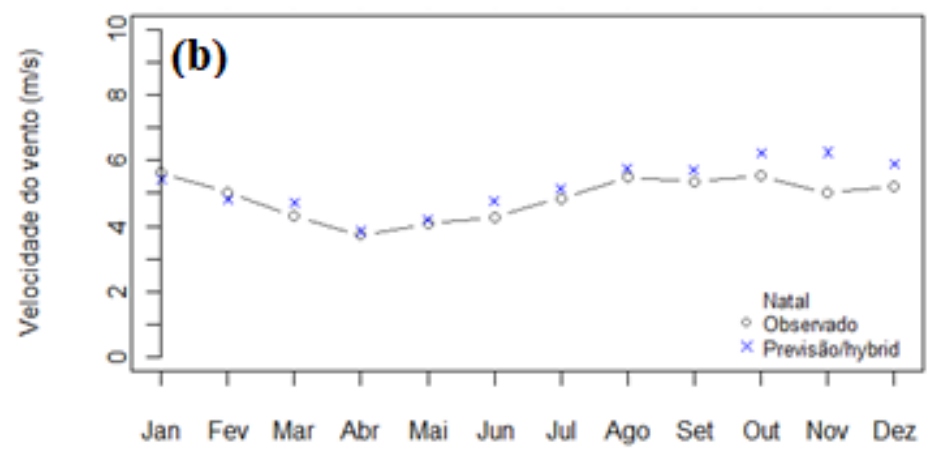

Figura 1 b - comparação da previsão x observado (ilustração).

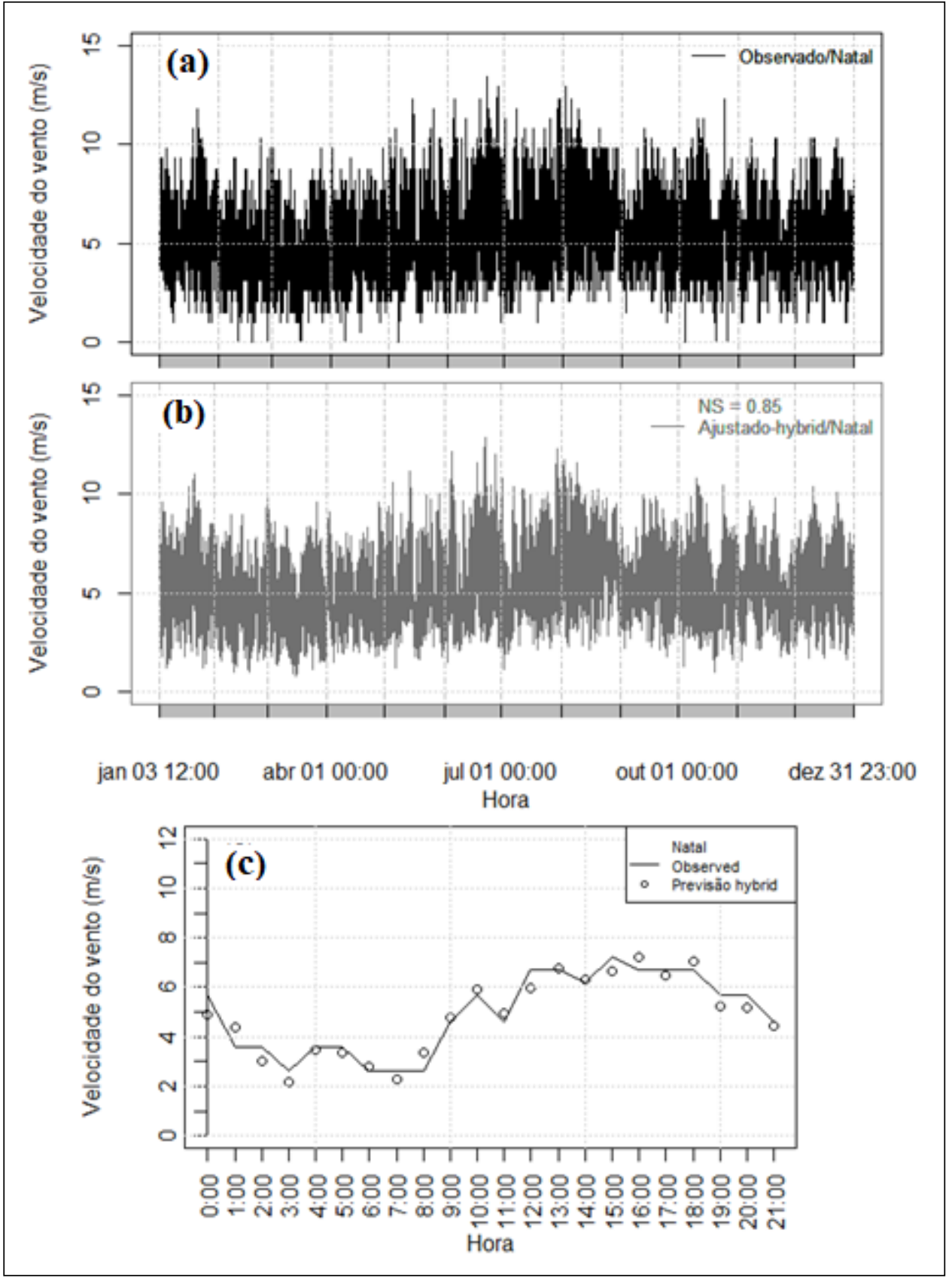

Figura 2 - Comparações entre as séries temporais, em relação aos horários do ano de 2014. (a) Observações (linha cor preta), (b) Ajustes pelo modelo hybrid (linha cor cinza) e (c) Para o dia seguinte, Observação (linha cor preta) e previsão pelo modelo hybrid (círculo). 
em termos de valores máximos e mínimos da velocidade do vento na maioria dos meses. Por exemplo, nas duas séries temporais (ajustada e observada) os valores de mínimo da velocidade do vento no ano de 2014 ocorreram no mesmo mês de abril, e também coincidiram nos seus valores em aproximadamente $4,0 \mathrm{~m} / \mathrm{s}$. Em termos de valores de máximo da velocidade do vento para o mesmo ano, o mês de outubro representa o período de ocorrência para as duas séries temporais (ajustada e observada) com valores próximos de $6,0 \mathrm{~m} / \mathrm{s}$.

Uma vez comprovado a boa qualidade do ajuste produzido pelo modelo hybrid, é possível esperar que ocorra precisão nas previsões da velocidade do vento, como se constata na figura $1 \mathrm{~b}$. As séries temporais previstas para o ano de 2015, ano seguinte aos dados ajustados são comparadas as séries temporais observadas para o mesmo ano. A série prevista consegue acompanhar o perfil da série observada, apresentando valores muito próximos entre si, por exemplo, os valores de mínimo da previsão e observação ocorrem no mesmo mês em abril e são similares em aproximadamente $4,0 \mathrm{~m} / \mathrm{s}$. Outro detalhe identificado a cerca da previsão, refere-se ao fato de que a mesma também consegue representar as características de sazonalidade existente da série observada, ou seja, menores e maiores intensidades da velocidade do vento de acordo com os diferentes períodos chuvosos e secos.

Em termos de médias horárias da velocidade do vento, a figura 2 mostra comparativo entre as séries temporais: observada, representada na figura $2 \mathrm{a}$ em linha cor preta; ajustada, conforme ilustração na figura $2 \mathrm{~b}$ em linha cor cinza; e também para os horários do dia 01/01/2015 seguinte ao ajuste, relacionando para esse período a previsão (em círculos) e observação (linha cor preta) representados na figura 2c. O valor do coeficiente de eficiência NS é de 0,85 o que demostra o perfeito ajuste aos dados observados. E em função deste resultado é possível identificar que a série temporal ajustada consegue reproduzir padrões de máximos e mínimos da velocidade do vento da série temporal observada em praticamente todo o período. No tocante a previsão, é possível identificar que a mesma consegue acompanhar o perfil da observação com valores similares entre si em especial nos horários diurnos entre 6:00h e 18:00h, exemplo disso, as 6:00h ocorre coincidência nos valores de mínimo em ambas as séries em aproximadamente $3,0 \mathrm{~m} / \mathrm{s}$. Os valores mais intensos de médias horárias da previsão da velocidade do vento em sua maioria encontram-se nos horários diurnos entre 6:00h e 18:00h, sendo que esses horários também estão de acordo com a maioria dos valores mais intensos encontrados para a série temporal observada.

É importante destacar que muito embora os resultados para as previsões da velocidade do vento nesse artigo foram apresentados ao nível de $10 \mathrm{~m}$ de altura, e na atualidade os aerogeradores no Brasil estão sendo implantados acima de $100 \mathrm{~m}$ de altura, conforme em $\mathrm{ABEE}$ lica $^{3}$, mas o modelo apresentado para as previsões não possui dependência de alturas, ou seja, pode ser testado sua viabilidade para qualquer nível de altura, para isso basta apenas entrar com a série temporal observada no hybrid para fornecer as possíveis projeções. Esse trabalho poderá auxiliar como uma possível ferramenta útil a ser utilizada em diversas áreas, por exemplo, no setor eólico, configurando-se em uma tentativa a mais de garantias aos tomadores de decisão do setor, tendo em vista, a possibilidade de realizar previsões da velocidade do vento local.

\section{Conclusões}

O modelo híbrido proposto com a finalidade de realizar previsões de médias mensais e horárias da velocidade do vento é eficiente na produção de ajustes aos dados observados. Essa afirmativa é baseada nas medidas de acurácia encontradas. Este fator favorece nas semelhanças de máximos e mínimos da velocidade do vento de ambas as séries temporais ajustadas e observadas. Esta análise certamente é responsável por proporcionar maiores precisões das séries temporais previstas, em termos de médias mensais e horárias. Foi possível identificar também que o modelo hybrid consegue representar características sazonais da velocidade do vento da região de estudo, ou seja, menores intensidades no período chuvoso, e também maiores intensidades para o período seco. Esse trabalho poderá auxiliar em diversas áreas de interesse em previsão de séries temporais, como é o caso do setor eólico, por exemplo, sendo possível adquirir informações importantes a cerca do potencial eólico local, o qual poderá ser aproveitado para possível geração de energia elétrica, ou seja, uma tentativa de fornecer garantias aos tomadores de decisão do setor na exploração dos ventos de uma dada região.

\section{Agradecimentos}

Os autores gostariam de agradecer ao Programa de Pós-Graduação em Ciências Climáticas (PPGCC) da Universidade Federal do Rio Grande do Norte (UFRN). Agradecimento por parte do autor correspondente ao apoio financeiro fornecido pela Agência Nacional de Petróleo (ANP) / PRH-51 a partir de bolsa de doutorado. Agradecimento por parte de co-autor ao apoio financeiro dado pelo Conselho Nacional de Desenvolvimento Científico e Tecnológico (CNPq) pela bolsa PQ2 - Proc. 301553/2016-5, e do Projeto de Pesquisa do CNPq - Proc. 400053/2014-4.

3 http://www.portalabeeolica.org.br/noticias/5283-torres-mais-altas-elevam-em-6-vezes-potencial-elico.html. Consultado em 11/01/2017. 


\section{Referências}

BROCKWELL, PJ, DAVIS, RA. Introduction to time series and forecasting. New York: Springer; 2016.

CAMELO, HN, LUCIO, PS, LEAL JUNIOR, JBV. Modelagem de média mensal de velocidade do vento para região litorânea no nordeste Brasileiro através do método aditivo Holt-Winters com vias a previsão de geração eólica. Revista Brasileira de Energias Renováveis 2016;5(4):17-29.

DAI, A. Increasing drought under global warming in observations and models. Nat. Clim. Change 2013;3(1):5258.

KAVASSERI, R, SEETHARAMAN, K. Day-ahead wind speed forecasting using f-ARIMA models. Renew. Energy 2009; 34(5):1388-1393.

LIU, H, TIAN, H, Li, Y. Comparison of two new ARIMA-ANN and ARIMA-Kalman hybrid methods for wind speed prediction. Appl. Energy 2012; 98(1):415 - 424.

PACHAURI, RK, MEYER, L, PLATTNER, GK, STOCKER, T. IPCC. Climate Change 2014: Synthesis Report. In: Contribution of Working Groups I, II and III to the Fifth Assessment Report of the Intergovernmental Panel on Climate Change. IPCC [Internet]; 2015 January 02 - 03; Geneva, Switzerland. 2015 [cited 2017 dec 07]. Available from: http://boris.unibe.ch/71642/.

SILVA, PMO, MELLO, CR, SILVA, AM, COELHO, G. Modelagem da hidrógrafa de cheia em uma bacia hidrográfica da região Alto Rio Grande. Revista Brasileira de Engenharia Agrícola e Ambiental 2008;12(3):258265.

ZHANG, G. Time series forecasting using a hybrid ARIMA and neural network model. Neurocomputing 2003;50(1):159-175.

\section{João Bosco Verçosa Leal Junior}

Henrique do Nascimento Camelo

Universidade Estadual do Ceará (UECE), Fortaleza, Brasil

Professor Associado, Curso de Física, E-mail: jblealjr@uece.br

Universidade Federal do Rio Grande do Norte (UFRN), Fortaleza, Brasil

Paulo Sérgio Lucio

Programa de Pós-Graduação em Ciências Climáticas, E-mail: henriquecamelo13@yahoo.com.br

Universidade Federal do Rio Grande do Norte (UFRN), Fortaleza, Brasil

Paulo Cesar Marques de Carvalho Programa de Pós-Graduação em Ciências Climáticas, E-mail: pslucio@ccet.ufrn.br

Universidade Federal do Ceará (UFC), Fortaleza, Brasil Departamento de Engenharia Elétrica, E-mail: carvalho@dee.ufc.br 